\title{
ANÁLISE PRELIMINAR DE GEOMORFOSSÍTIOS DA ESCARPA DA ESPERANÇA - PARANÁ
}

\author{
Julio Manoel França Silva $^{(\mathrm{a})}$, Chisato Oka-Fiori ${ }^{(\mathrm{b})}$, Luiz Carlos Basso ${ }^{(\mathrm{c})}$ \\ (a) Professor, Departamento de Geografia, UNICENTRO, juliosilva.geografo@gmail.com \\ (b) Professora, Departamento de Geografia, UFPR, chisatofiori@gmail.com \\ (c) Professor, Departamento de Geografia, UNICENTRO, bassolc4@ gmail.com
}

\section{Eixo: GEODIVERSIDADE, GEOARQUEOLOGIA E PATRIMÔNIO NATURAL}

\section{Resumo}

O presente trabalho aborda o conceito de Geomorfossítio - correlato ao de Geodiversidade, e sua aplicação na Escarpa da Esperança (PR). Buscando representar diversificados contextos geomorfológicos e identificar suas potencialidades e vulnerabilidades de uso, apresenta-se uma classificação em quatro níveis analíticos que, por sua vez, agregam oito geomorfossítios amostrais, quais sejam: Escarpas Festonadas (Salto/Canyon do Rio São Francisco e Saltos Gêmeos); Formas Triangulares (Vale do Rio Charqueadas e Cabeceiras do Rio São João); Relevos Residuais (Morro do Chapéu e Morro do Pico Agudo); e Formas Elevadas (Crista Planáltica e Divisor Interplanáltico). Vislumbra-se oferecer subsídios a estudos posteriores que visem identificação de seus valores patrimoniais.

Palavras chave: Geodiversidade, Diversidade Geomorfológica, Patrimônio Geomorfológico.

\section{Introdução}

O interesse na preservação e divulgação da variabilidade abiótica da Terra tem aumentado nos últimos anos, concomitantemente às preocupações ambientais de nível global e/ou regional (PEREIRA et al., 2007); encontrando no conceito de Geodiversidade (DIXON, 1996; STANLEY, 2000; GRAY, 2004; KOZLOWSK, 2004) e outros dele derivados, subsídios teóricos e metodológicos.

Um desses conceitos correlatos é o de Geomorfossítio, que pode ser entendido como uma forma de relevo potencialmente atribuída de valores (ex. cênico, socioeconômico, cultural, científico e turístico) que expressam a variabilidade e os significados geomorfológicos de uma paisagem, condições que podem qualifica-los como integrante do patrimônio natural de um determinado recorte espacial (PANIZZA, 2001); tendo sido adotado, por exemplo, por Carton et al. (2005), Pralong (2005), Pereira (2007) e Reynard et al. (2011).

Mesmo reconhecendo a importância de uma análise integrada dos elementos que compõe a geodiversidade, o presente trabalho considera, especificamente, Geomorfossítios existentes na Escarpa da Esperança e seus potenciais valores; especificamente no setor norte da APA da Serra da Esperança, localizado entre os municípios paranaenses de Guarapuava e Prudentópolis (Figura 1). 


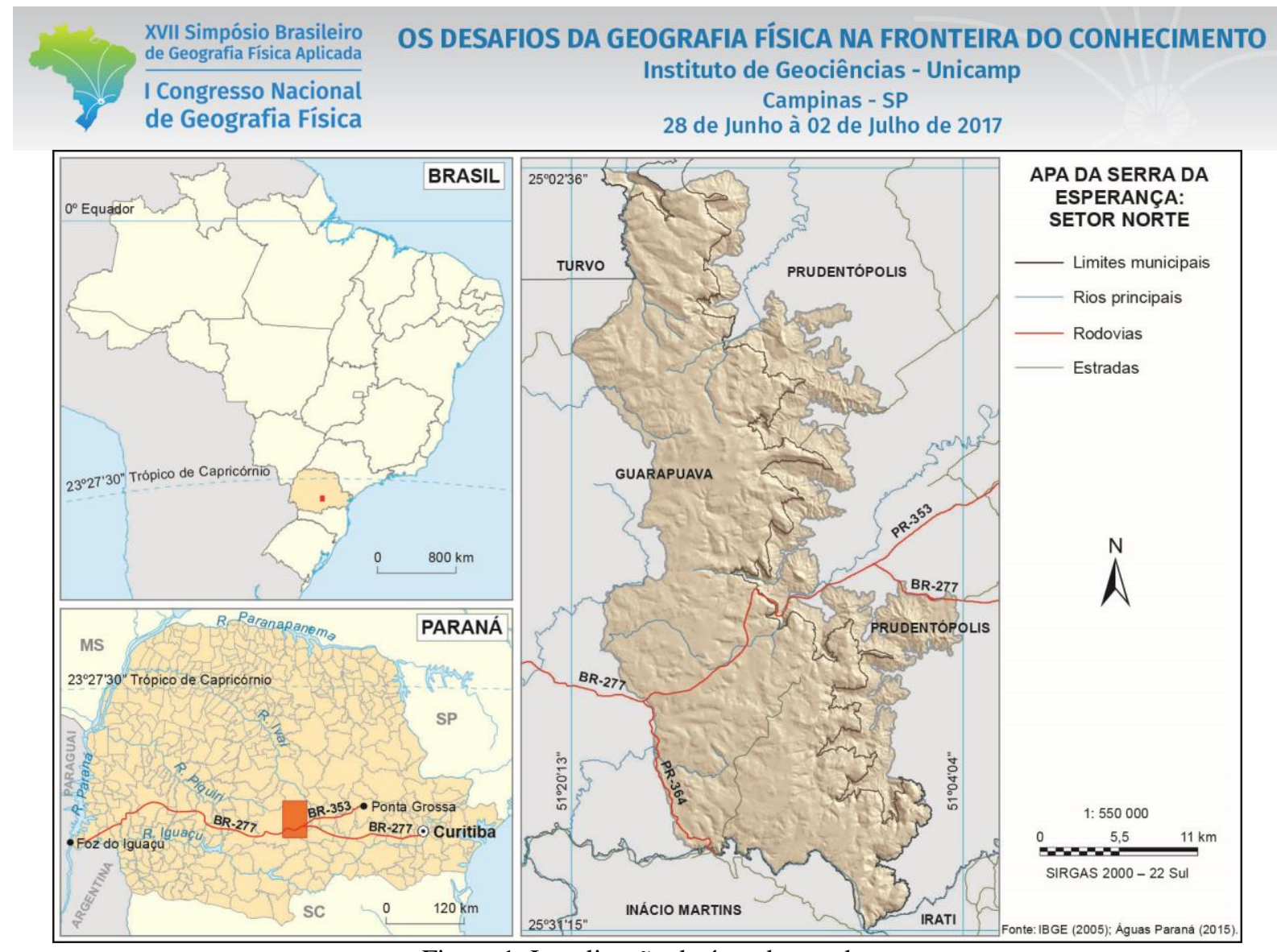

Figura 1: Localização da área de estudo.

A Escarpa da Esperança pode ser compreendida como um grande degrau fisiográfico que demarca geomorfologicamente a transição entre o Segundo Planalto e Terceiro Planalto Paranaense; por sua vez, esculpidos, respectivamente, sobre rochas paleozoicas - Formações Teresina e Formação Rio do Rasto; e mesozoicas - Formação Serra Geral e Formação Piramboia-Botucatu (MINEROPAR, 2001).

Além de características herdadas inerentemente desta faixa de transição, sua configuração geomorfológica é amplamente influenciada por lineamentos estruturais, estes, associados a linhas de fraqueza préexistentes no embasamento da Bacia do Paraná (SOARES et al., 1982). Quando foram reativados em fases tectônicas posteriores, determinaram a direção de sistemas de falhas subsequentes; em algumas situações funcionando como dutos para intrusão de enxame de diques e de soleiras de diabásio (MILANI, 1997).

Geomorfologicamente a área apresenta padrões em planícies aluviais estreitas, cristas controladas por lineamentos estruturais, faixas de cornija, depósitos de tálus e relevos residuais; que quando agrupados nas subunidades morfoesculturais definidas por Santos et al. (2006) podem classificados como:

- Colinas amplas e planícies aluviais do Planalto Pitanga/Ivaiporã e do Planalto Foz do Areia, inseridas na unidade morfoescultural Terceiro Planalto Paranaense; 
- Cristas alongadas e colinas amplas do Planalto de Prudentópolis; pertencente a unidade morfoescultural Segundo Planalto Paranaense; e

- Faixas de cornijas, depósitos de tálus e relevos residuais dos Planaltos Residuais da Formação Serra Geral; representativos das formas de relevo ocorridas na transição geológicogeomorfológica existente entre os dois grandes planaltos, ou seja, a Escarpa da Esperança.

O objetivo geral do presente trabalho refere-se ao levantamento qualitativo de geomorfossítios amostrais na área de estudo; propondo uma classificação que reúne informações das suas características geomorfológicas, de suas potencialidades e vulnerabilidades físicas e em relação ao seu uso e gestão.

As características dos geomorfossítios selecionados devem ser capazes de fornecer subsídios preliminares para o entendimento dos processos envolvidos na sua gênese e evolução; e indicar potenciais valores patrimoniais.

\section{Métodos e procedimentos}

\subsection{Considerações gerais}

Avaliando que os geomorfossítios selecionados desenvolvem-se sobre condições de borda planáltica, sua descrição considera os modelos teóricos desenvolvidos para este contexto geomorfológico (KING, 1956; AB' SABER, 1975; MAACK, 1981; BIGARELLA et al.,1994).

Conforme referenciado anteriormente, o conceito de geomorfossítio remete a locais que, dotados de características superlativas, são consideradas as unidades melhor indicadas para o desenvolvimento de estratégias para uso sustentável dos valores do componente geomorfológico da geodiversidade.

Os critérios de escolha e delimitação dos geomorfossítios basearam-se na capacidade de certos locais serem:

- Indicadores dos fatores físicos desencadeadores da diversidade geomorfológica;

- Representativos de formas, processos e objetos geomorfológicos; e

- Visualizados em escalas de campo compatíveis ao seu aproveitamento científico, didático e/ou turístico.

\subsection{Geoprocessamento}

Apoiando-se nos dados processados em SIG e imagens digitais, consideraram-se os procedimentos abaixo indicados: 
- Delimitação poligonal e estabelecimento de níveis de observação;

- Representação tridimensional por meio de: plataforma Google Earth Pro, módulo ArcScene do ArcGIS 10.1 e fotografias de campo.

\subsection{Análise qualitativa}

Levando em conta o conhecimento bibliográfico e empírico da área de estudo, compreende utilização de aparelho de georreferenciamento (Garmin GPSMAP 62), máquina fotográfica de lente cambiável (Nikon D7000) e ficha de campo; sendo esta última definida mediante adaptação das metodologias de Pereira $e t$ al. (2007), Pereira e Pereira (2010) e Bollati et al.(2013), propondo-se a identificação e avaliação dos geomorfossítios em campo de acordo com:

- Escala de observação: Panorâmica, Local ou Isolada;

- Indicadores geomorfológicos: Morfologia, Morfodinâmica e Morfogênese;

- Particularidades e potenciais valores: Científico, Didático e Turístico;

- Correlação com classes de uso e ocupação da terra;

- Zonas de planejamento: São Francisco, Manancial do Rio das Pedras, Serra da Esperança, Guairacá ou Guarapuava;

- Situação administrativa: Estadual ou Privada; e

- Indicadores de Riscos e Vulnerabilidades.

\section{Resultados}

\subsection{Classificação dos geomorfossítios}

Sendo a Escarpa da Esperança a borda oriental dos derrames basálticos mesozoicos, bem como os arenitos a eles intercalados, o termo Serra da Esperança especifica as formas e feições de relevo que evoluíram condicionados pelos lineamentos estruturais mencionados, algumas das quais com peculiaridades que permitem sua designação como geomorfossítios, que, por sua vez, conforme proposta de classificação compõem quatro níveis analíticos distintos: Escarpas Festonadas, Formas Triangulares, Relevos Residuais e Formas Elevadas (Figura 2). 

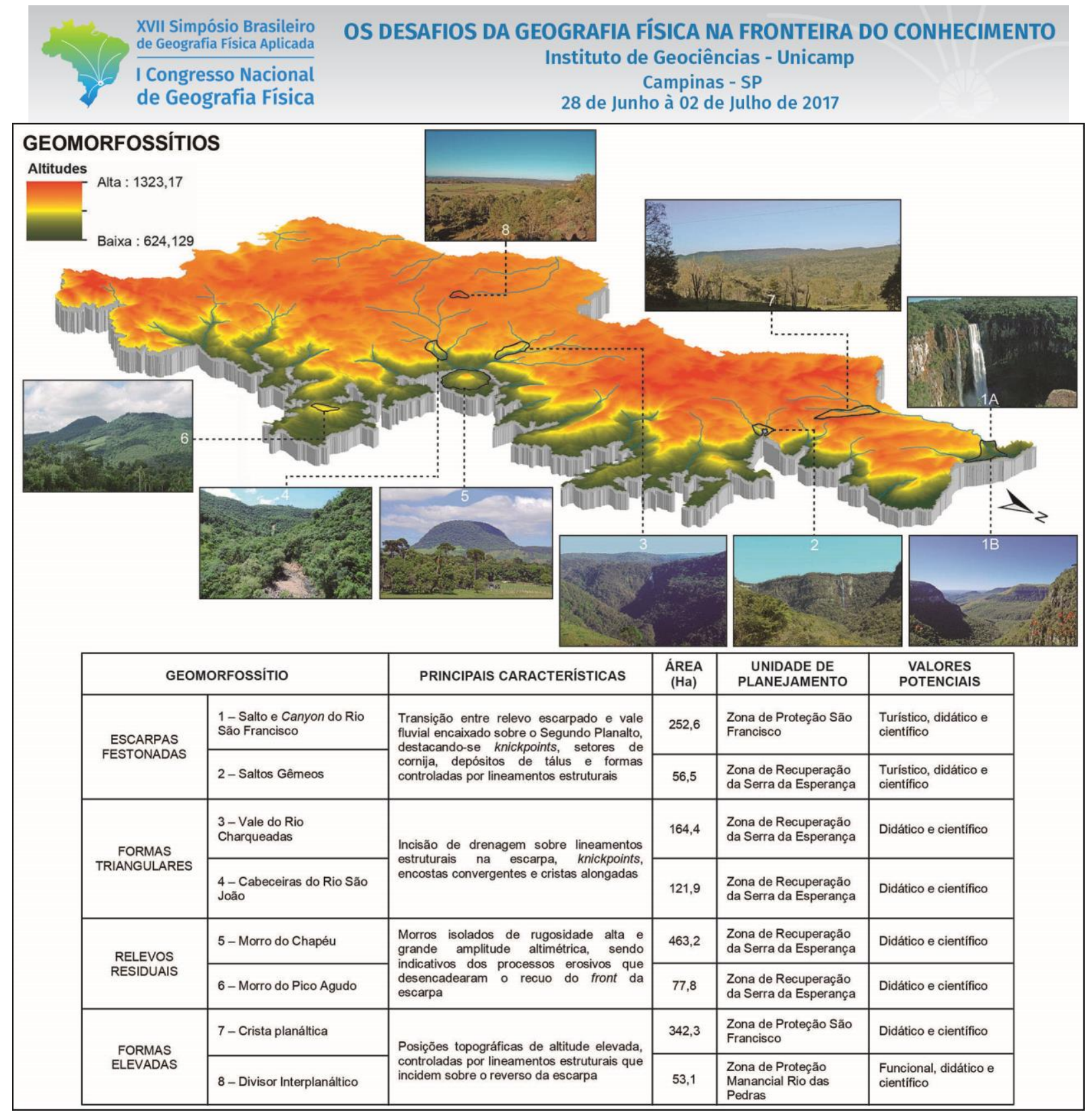

Figura 2 - Localização dos geomorfossítios selecionados na área de estudo.

\subsection{Escarpas festonadas}

O Rio São Francisco, integrante do sistema hidrográfico do Rio Ivaí, nasce no Terceiro Planalto em uma altitude aproximada de 1.160 metros, percorrendo 11,4 km até a Escarpa da Esperança, no extremo norte da área de estudo. A alteração abrupta do perfil longitudinal do rio é decorrente da alta declividade da cornija da escarpa, que neste setor da APA é controlada por lineamento estrutural, determinando a formação de uma queda d'água de 196 metros sobre afloramento da Formação Piramboia-Botucatu (mesozoica), cuja base define o retorno ao seu estado de equilíbrio, considerando os pressupostos da geomorfologia fluvial (CHRISTOFOLETTI, 1981; SCHUMM et al., 2002; PHILLIPS et al., 2010); já sobre a Formação Rio do Rasto (paleozoica). 


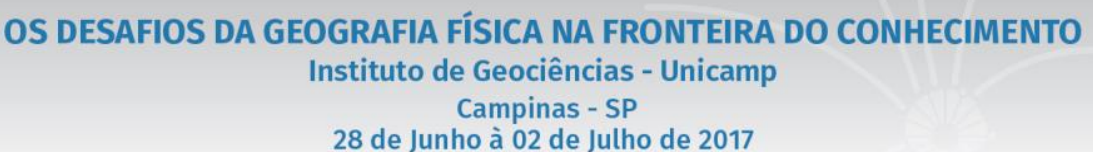

28 de Junho à 02 de Julho de 2017

O geomorfossítio em questão refere-se a um polígono de 252,6 hectares (ha) estabelecido no entorno do Salto São Francisco e seu vale à jusante, cuja amplitude altimétrica, bastante significativa, possibilita a designação deste último como canyon.

Considerando a escala de campo verificam-se espessos setores da cornija que indicam frentes mais resistentes ao intemperismo físico, determinando, em compensação, que processos de erosão regressiva passem a agir preferencialmente sobre o front da escarpa, causando seu festonamento e originando canyon de pequena extensão sobre as rochas sedimentares paleozoicas.

Este contexto geomorfológico também é verificado em outras posições da Escarpa, inclusive formando quedas d'água com características parecidas, tal como ocorre com o segundo geomorfossítio selecionado; cuja delimitação poligonal, de 56,6 ha de área, decorreu-se no entorno dos saltos Barra Grande e Fazenda Velha, que devido sua proximidade e similaridade, recebem localmente a denominação Saltos Gêmeos; aqui considerada.

Cabe destacar, no entanto, que o processo de festonamento neste último é menor em comparação ao primeiro geomorfossítio, condição hipoteticamente atribuída ao lineamento existente no vale do Rio da Barra Grande, para onde os dois saltos convergem, dividindo o geomorfossítio em dois setores de vertentes: um orientado a sudeste, submetido ao controle estrutural de maneira mais acentuada; e outro orientado a noroeste, de controle menos evidente, onde a escarpa, como consequência, recua de maneira relativamente acelerada.

Em relação ao uso e cobertura da terra, os dois geomorfossítios desta categoria de análise (escarpas festonadas) apresentam-se bem protegidos, com vegetação natural bastante conservada dentro dos seus limites. Suas adjacências, no entanto, são ocupadas por culturas agrosilvopastoris, condição que contradiz parte das estratégias de manejo estipuladas por Oliveira et al. (2009) nas duas zonas de planejamento que os agregam, respectivamente: a) Zona de Proteção São Francisco - voltada a proteção dos remanescentes de vegetação nativa e regulamentação do turismo; e b) Zona de Recuperação da Serra da Esperança direcionada, especificamente, a recuperação de ecossistemas regionais, preservação das áreas de recarga do Aquífero Guarani e proteção da Escarpa da Esperança, bem como seu entorno imediato.

Por outro lado, além dos valores didáticos e científicos que lhes são inerentes, os dois sítios geomorfológicos possuem elevado valor turístico, atendendo, potencialmente, as demandas de dois importantes segmentos da atividade turística: o Ecoturismo e o Geoturismo, este último designando:

A provisão de serviços e facilidades interpretativas que permitam aos turistas adquirirem conhecimento e entendimento da geologia e geomorfologia de um sítio (incluindo sua contribuição para o desenvolvimento das ciências da Terra), além de mera apreciação estética (HOSE, 1997, p. 9). 


\subsection{Formas Triangulares}

A designação Formas Triangulares foi adotada em referência a dois locais de interesse geomorfológico, referentes a posições na escarpa controladas por lineamentos transversais, os quais são responsáveis pela configuração triangular do front da Escarpa.

O Geomorfossítio Vale do Rio Charqueadas especifica um polígono que possui 164,3 ha de área, delimitado entre as cabeceiras e o terço superior deste curso hídrico, onde são constatadas as influências dos lineamentos estruturais na erosão diferencial e recuo da escarpa, fazendo aflorar os arenitos da Formação Piramboia-Botucatu.

Estas características resultam em knickpoints, encostas íngremes e convergência hídrica, formando vale fluvial encaixado que denota a imposição de cursos anaclinais no front da escarpa, o que Ab'Saber (1975) designa como percées anaclinais, na especificação de afluentes que correm em sentido inverso ao mergulho das camadas da cuesta.

Sobre o plano de manejo da APA, este local está inserido na Zona de Recuperação da Serra da Esperança, com vegetação natural bastante representativa espacialmente, embora se verifique atividade pecuária na posição superior de vertentes menos íngremes, particularmente naquelas adjacentes a margem esquerda do Rio Charqueadas.

No que diz respeito aos potenciais valores patrimoniais, destaca-se a relativa facilidade de acesso e de visualização dos pontos de interesse, embora o local esteja inserido em propriedade particular, o que pode dificultar o desenvolvimento de eventuais atividades destinadas ao seu uso científico, didático e turístico.

Igualmente representativo das Formas Triangulares, o geomorfossítio Cabeceiras do Rio São João possui 121,9 ha de área, cujo polígono abrange um setor da escarpa submetido aos mesmos processos morfogenéticos anteriormente explicitados, sobretudo em relação à subdivisão das encostas em facetas triangulares e controle dos cursos hídricos por estruturas lineares.

Sua escolha como sítio geomorfológico é fundamentada por abrigar áreas onde às funções morfogenéticas do Rio São João - importante afluente do Rio Avaí - é bastante significativa, apresentando, ao longo do seu percurso, diversificados valores patrimoniais em potencial.

Especificamente no polígono delimitado, tais valores referem-se a local de interesse didático e científico que ilustram a variabilidade de formas existentes na transição entre o Terceiro e Segundo Planalto Paranaense, derivadas das respectivas formações geológicas, associadas a falhas, fraturas e diques de diabásio, que além de definirem o limite entre setores superiores e inferiores das vertentes, controlam os canais de primeira ordem tributários do Rio São João. 
As características deste geomorfossítio exemplificam os processos morfogenéticos atuantes na Serra da Esperança, os quais são derivados da sua vulnerabilidade física potencial (ex. declividade alta, solos rasos) e da gradual destituição da vegetação natural para fins agropecuários, tanto na Zona de Conservação de Guarapuava, a montante dos limites definidos; quanto na Zona de Recuperação da Serra da Esperança, onde está inserido.

Algumas evidências de eventos recentes são constatadas, tais como cicatrizes de deslizamento no front da Escarpa e a deposição de sedimentos e detritos sobre o vale fluvial que se concentram exatamente no ponto onde o Rio São João inicia seu percurso sobre as rochas sedimentares da Formação Rio do Rasto.

\subsection{Relevos Residuais}

Os relevos residuais referem-se a morros testemunhos indicativos do recuo da escarpa, os quais foram denominados por Santos et al. (2006) como Planaltos Residuais da Formação Serra Geral, em referência a formas de relevo que configuram-se como morros isolados de elevada amplitude altimétrica, cujos valores máximos são similares aos encontrados nas áreas mais elevadas da cuesta. A esta característica, somam-se as formações geológicas que os estruturam, que sendo distintas à geologia circundante, indicam formas de relevo resistentes aos processos morfogenéticos, podendo ser denominada como relevos residuais.

Quando correlacionados ao modelo teórico de King (1956) a interpretação dos relevos residuais da área de estudo deve considerar a função do recuo paralelo do front da escarpa por desagregação gravitacional; característica por ele designada como pediplanação ou superfície de aplainamento, que denota a evolução horizontal do relevo sob clima árido ou semiárido. Neste contexto, os relevos residuais ou morros testemunhos, referem-se a superfícies mais resistentes a atividade erosiva, isoladas das frentes de dissecação por lineamentos estruturais mesozoicos, que determinariam, preferencialmente, a incisão de drenagem e, consequentemente, o recuo das vertentes, nas áreas contíguas.

Para representação dos processos geomorfológicos mencionados foram considerados dois geomorfossítios na área de estudo: o primeiro denominado Morro do Chapéu e o segundo Morro do Pico Agudo expressões locais já popularizadas na literatura científica (MAACK, 1981; SANTOS et al. 2006; OLIVEIRA et al., 2009).

O Geomorfossítio Morro do Chapéu possui área de 463,2 ha, abrangendo áreas de topo, onde afloram basaltos da Formação Serra Geral; vertentes superiores, bastante íngremes, modeladas sobre os arenitos da Formação Botucatu; e vertentes inferiores, suaves, modeladas sobre a Formação Rio do Rasto (Segundo Planalto), que sendo de idade permiana, interdigita-se às formações mesozoicas mencionadas, devido estar 
condicionada por lineamentos estruturais (fraturas e falhas), o que as distinguem do nível altimétrico geral das áreas aplainadas típicas, em suas adjacências.

Em relação ao plano de manejo da APA, o Morro do Chapéu está inserido na Zona de Recuperação da Serra da Esperança, que ao contrário das diretrizes específicas determinadas, não é efetiva no controle da silvicultura e da agropecuária.

Os remanescentes florestais são restritos ao topo e vertentes superiores, que amplamente acidentados, dificultam a mecanização e uso nas atividades mencionadas. Por outro lado, mesmo diante da fragilidade emergente, este sítio geomorfológico possui valor científico, didático e turístico; sendo detentor de variados pontos de visualização panorâmica, destacando-se aqueles inseridos sobre o front e cornija da Escarpa da Esperança.

O Geomorfossítio Morro do Pico Agudo possui área de 77,8 ha e seu topo possui nível altimétrico similar $(1.060 \mathrm{~m})$ às posições mais elevadas do front da escarpa, compreendendo a mesma litologia desta, ou seja, basaltos e arenitos das formações Serra Geral e Piramboia-Bocucatu. Seu controle estrutural é realizado por falhas, preenchidas por diques, que demarcam o isolamento de três superfícies elevadas distintas, que em conjunto às vertentes adjacentes, definiram seus limites poligonais em SIG.

Sua visualização panorâmica é propiciada, especialmente, a partir do Segundo Planalto, nas proximidades da rodovia BR-277 e em setores da Estrada do Tijuco Preto; assim denominada por ser o principal acesso ao distrito homônimo, pertencente ao município de Prudentópolis.

Em que pese o eventual uso dos seus valores didáticos e científicos, o Morro do Pico Agudo, também está localizado na Zona de Recuperação da Serra da Esperança, apresentando as mesmas vulnerabilidades atribuídas à silvicultura e agropecuária, responsáveis por destituir amplamente sua vegetação natural. O fato de estar inserido em propriedade privada, somada a fiscalização ambiental ineficiente, dificulta o cumprimento das estratégias definidas para aquela zona de planejamento da APA, impondo desafios para eventuais estratégias de preservação e uso como patrimônio geomorfológico.

\subsection{Formas Elevadas}

As formas elevadas referem-se a posições topográficas sobre o reverso da escarpa que apresentam os maiores valores de altitude no Terceiro Planalto Paranaense, destacando-se na paisagem como formas de topo arredondado ou cristas alongadas, normalmente controladas pelos lineamentos estruturais que incidem os basaltos da Formação Serra Geral. 


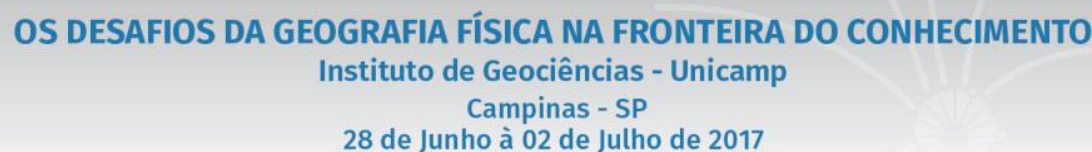

28 de Junho à 02 de Julho de 2017

Para representação das formas de relevo elevadas no reverso da escarpa, foram selecionados dois locais de interesse geomorfológico, denominados Geomorfossítio Crista Planáltica e Geomorfossítio Divisor Interplanáltico, os quais apresentam topos situados, respectivamente, a 1.253 e 1.275 metros de altitude.

O Geomorfossítio Crista Planáltica possui área de 53,1 ha, e apresenta-se geomorfologicamente como uma forma alongada, preferencialmente orientada a sudoeste, configurando-se em vertentes côncavas que convergem para a nascente do Rio São Francisco, que por sua vez, flui em direção norte através de leito fluvial estruturalmente controlado.

A influência dos lineamentos estruturais na distribuição da declividade, umidade topográfica e posição topográfica, é bastante significativa, considerando que os limites dos padrões espaciais apresentados por estes parâmetros, são muito similares a orientação de dique, falhas e fraturas que incidem neste sítio geomorfológico.

Em termos de uso e planejamento da APA, este local está inserido integralmente na Zona de Proteção do Rio São Francisco, cuja visualização panorâmica é viabilizada mediante a Estrada de Guairacá, que permite o acesso ao distrito homônimo, no município de Guarapuava, e ao Salto São Francisco, anteriormente caracterizado. Apresentando potenciais valores patrimoniais, particularmente didáticos e científicos, encontra-se atualmente sobre domínio privado, inclusive recoberto significativamente pela silvicultura, reiterando a ineficiência no cumprimento das diretrizes estipuladas pelo plano de manejo da APA, especificamente na zona de planejamento mencionada.

A denominação Divisor Interplanáltico foi adotada em referência ao último geomorfossítio selecionado, se referindo à polígono delimitado no entorno de relevo em crista, destacando-se em termos altitudinais em comparação ao nível geral do reverso da escarpa, igualmente condicionada por lineamentos estruturais.

Este é o menor geomorfossítio avaliado, possuindo apenas 53,1 ha de área total, demarcando dois sentidos opostos de drenagem: um que converge para o Terceiro Planalto, na mesma direção do reverso da Escarpa, compondo a Bacia Rio das Pedras, esta, por sua vez, integrante da Bacia do Rio Iguaçu; e outro em direção ao Segundo Planalto, formando os canais de primeira ordem da Bacia do Rio São João que, reiterando, compõe o sistema hidrográfico do Rio Ivaí.

Sua visualização panorâmica é possível a partir de diferentes pontos adjacentes, destacando-se aqueles localizados as margens da rodovia BR-277. A unidade de planejamento onde está inserido é a Zona de Proteção Manancial Rio das Pedras, condição que inerentemente já o capacitaria para ser abordado como recurso patrimonial, levando em conta a importância da sustentabilidade de uso dos recursos hídricos e 
seus valores didáticos e científicos, diretamente vinculados a algumas funções geomorfológicas específicas.

De maneira geral, este geomorfossítio está bem preservado, embora a atual ocupação do topo, mais notadamente por moradias e antenas de telecomunicação, represente possíveis fatores emergentes de fragilidade ambiental.

\section{Conclusão}

Os aspectos geomorfológicos interpretados em cada geomorfossítio estão em consonância aos encontrados nos modelos teóricos destinados a elucidação dos fatores envolvidos na gênese de relevos de transição planáltica, destacando-se a função da Escarpa da Esperança e incisão de lineamentos estruturais e rede de drenagem, os quais possuem ampla participação na evolução geomorfológica.

O aproveitamento dos valores didáticos, científicos e turísticos, dentro das premissas da geodiversidade e geoconservação, poderia ser contextualizado nas diretrizes definidas no plano de manejo da APA, inserindo-se nas zonas de planejamento do setor analisado.

A atual prioridade aos aspectos da biodiversidade não seria um impeditivo a estratégias exclusivamente direcionadas aos componentes geomorfológicos da paisagem; condição intrínseca e superlativa analisada no recorte espacial como um todo ou nos geomorfossítios amostrais.

Cabe destacar que a quantificação patrimonial destes locais não foi tema deste trabalho, já que este contexto demanda abordagens metodológicas específicas. Por este motivo, os valores didáticos, científicos e turísticos foram considerados pela sua potencialidade de uso, sendo necessários estudos complementares para avaliar quantitativamente seu nível de representatividade.

\section{REFERÊNCIAS}

AB’ SABER, A. N. Formas do Relevo. São Paulo: Edart, 1975.

ÁGUAS PARANÁ - Instituto das Águas Do Paraná. Mapas e Dados Espaciais. Disponível em: http://www.aguasparana.pr.gov.br. Acesso em: 5 abril 2016.

BIGARELLA, J. J.; BECKER, R. D.; SANTOS, G. F. Estrutura e origem das paisagens tropicais e subtropicais. Vols. I e II. Florianópolis: Ed. UFSC, 1994.

BOLLATI, I.; SMIRAGLIA, C.; PELFINI, M. Assessment and Selection of Geomorphosites and Trails in the Miage Glacier Area (Western Italian Alps). Environmental Management, n. 51:951-967, 2013.

CARTON, A.; CORATZA, P.; MARCHETTI, M. Guidelines for geomorphological sites mapping: examples from Italy. Géomorphologie: relief, processus, environnement, v. 3, p. 209-217, 2005.

CHRISTOFOLETTI, A. Geomorfologia fluvial. São Paulo: Ed. Edgard Blücher Ltda, 1981.

DIXON, G. Geoconservation: An International Review and Strategy Significance on Tasmania. Occasional Paper, n. 35, Parks \& Wildlife Service, Tasmania. 1996.

GRAY, M. Geodiversity: Valuing and conserving abiotic nature. Londres: John Wiley \& Sons Ltda, 434 p., 2004.

DOI - 10.20396/sbgfa.v1i2017.1971 - ISBN 978-85-85369-16-3 
HOSE, T. A. Geotourism - Selling the Earth to Europe. In: MARINOS, P. G.; KOUKIS, G. C.; TSIAMBAOS, G. C.; STOURNAS, G. C. (Eds.). Engineering Geology and the Environment. Roterdam (Netherlands): Balkema, 1997.

IBGE - Instituto Brasileiro de Geografia e Estatística. Atlas nacional digital. Rio de Janeiro: IBGE, 2005.

KING, L. C. A Geomorfologia do Brasil Oriental. Revista Brasileira de Geografia, v. 18, n. 2, p. 3-121, abr./jun.,1956.

KOZLOWSKI, S. The concept and scope of geodiversity. Przeglad Geologiczny, v.52, n.8/2, p.833-837, 2004. Disponível em: www.pgi.gov.pl/pdf/pg_2004_08_2_22a.pdf. Acesso em: 10 jan. 2013.

MAACK, R. Geografia Física do Estado do Paraná. $2^{\text {a }}$ ed. José Olympio, Rio de Janeiro, 1981.

MILANI, E.J. Evolução tectono-estratigráfica da Bacia do Paraná e seu relacionamento com a geodinâmica fanerozóica do Gondwana Sul-ocidental. Tese (Doutorado em Geologia). Instituto de Geociências, Universidade Federal do Rio Grande do Sul, 1997, 255 p.

MINEROPAR (SERVIÇO GEOLÓGICO DO PARANÁ). Atlas geológico do Estado do Paraná. 2001. Disponível em <http/www.mineropar.gov.pr.br>. Acesso em 10 de jul. 2016.

OLIVEIRA, K. L.; BORN, P. A.; FICHER, D.; BONILAURI, F. Conservação e desenvolvimento na APA da Serra da Esperança. Curitiba: Mater Natura - Instituto de Estudos Ambientais, 2009, 44 p.

PANIZZA, M. Geomorphosites: Concepts, methods and examples of geomorphological survey. Chinese Science Bulletin, n. 46, p. 4-6, 2001.

PEREIRA, D. I.; PEREIRA, P., ALVES, M. I. C.; BRILHA, J. Avaliação do Património Geomorfológico: proposta de metodologia. Lisboa: Publicações da Associação Portuguesa de Geomorfólogos, v. 5, p. 235-247, 2007.

PEREIRA, P.; PEREIRA, D. Methodological guidelines for geomorphosite assessment. Géomorphologie: relief, processus, environnement, n. 2, p. 215-222, 2010.

PHILLIPS, J. D.; McCORMACK, S.; DUAN, J.; RUSSO, J. P.; SCHUMACHER, A. M.; TRIPATHI, G. N.; BROCKMAN, R. B.; MAYS, A. B.; PULUGURTHA, S. Origin and interpretation of knickpoints in the Big South Fork River Basin, Kentucky-Tennessee. Geomorphology, v. 114, n. 3, p. 188-198, 2010.

PRALONG, J.P. A method for assessing tourist potential and use of geomorphological sites. Géomorphologie: relief, processus, environment, n. 3, p. 189-196, 2005.

REYNARD, E.; CORATZA, P.; GIUSTI, C. Geomorphosites and Geotourism. Geoheritage, n. 3, p. 129-130, 2011.

SANTOS, L. J. C.; OKA-FIORI, C.; CANALI, N. E.; FIORI, A. P.; SILVEIRA, C. T.; SILVA, J. M. F.; ROSS, J. L. S. Mapeamento geomorfológico do estado do Paraná. Revista Brasileira de Geomorfologia, ano 7, n. 2, p. 03-12, 2006.

SCHUMM, S.; DUMONT, J.; HOLBROOK, J. Active Tectonics and Alluvial Rivers. Cambridge University Press, 2002, $292 \mathrm{p}$.

SOARES, P. C.; BARCELlOS, P. E.; CSORDAS, S. M.; MATTOS, J. T.; BALIEIRO, M. G.; MENESES, P. R. Lineamentos em imagens Landsat e Radar e suas implicações ao conhecimento tectônico da Bacia do Paraná. In: Anais do II Simpósio Brasileiro de Sensoriamento Remoto. Brasília, DF: INPE, 1982, p. 143-456.

STANLEY, M. Geodiversity. In: BARETTINO, D., WINBLEDON, W. A. P., GALLEGO, E. (Eds.). Geological heritage: its conservation and management. Madrid: ITGE, p. 15-18, 2000. 